\title{
A multidimensional examination of marital conflict and subjective health over 16 years
}

\author{
M. Rosie Shrout ${ }^{1}$ (1) । Randal D. Brown ${ }^{2}$ | Terri L. Orbuch ${ }^{3,4}$ । \\ Daniel J. Weigel $^{5}$
}

${ }^{1}$ Institute for Behavioral Medicine Research, The Ohio State University College of Medicine, Columbus, Ohio

${ }^{2}$ Center for Human Sexuality Studies, Widener University, Chester, Pennsylvania

${ }^{3}$ Department of Sociology, Oakland University, Rochester, Michigan

${ }^{4}$ Institute for Social Research, University of Michigan, Ann Arbor, Michigan

${ }^{5}$ Human Development and Family Studies/Cooperative Extension, University of Nevada, Reno, Reno, Nevada

\section{Correspondence}

M. Rosie Shrout, Institute for Behavioral Medicine Research, The Ohio State University College of Medicine, 460 Medical Center Drive, Columbus, $\mathrm{OH}$ 43210.

Email: rosie.shrout@osumc.edu

\section{Funding information}

National Institute of Child Health and Human Development, Grant/Award Number: HD40778; Russell J. and Dorothy S. Bilinski Educational Foundation

\begin{abstract}
Guided by stress process perspectives, this study conceptualizes marital conflict as a multidimensional stressor to assess how three aspects of conflict-frequency of disagreements, breadth of disagreements, and cumulative disagreements-impact subjective health. Longitudinal data of married couples spanning 16 years ( $n=373$ couples) were analyzed using multilevel modeling. For husbands, more frequent disagreements than usual within a given year were associated with poorer subjective health. For wives, the greater cumulative effects of disagreements over 16 years were harmful for subjective health. We discuss how gendered self-representations and relationship power issues help explain the findings. This research demonstrated the importance of examining multiple aspects of marital conflict to reveal that their subjective health consequences function differently for wives and husbands.
\end{abstract}

\section{K E Y W O R D S}

conflict, dyadic data analysis, gender differences, health, marriage

\section{1 | INTRODUCTION}

The health-enhancing effects of marriage are well documented. Married individuals tend to fare better on subjective and objective indicators of health compared to nonmarried individuals, including

As part of IARR's encouragement of open research practices, the authors have provided the following information:

This research was not pre-registered. The data and materials used in the research are available by emailing:

Rosie.Shrout@osumc.edu. 
having lower mortality and morbidity rates (Kaplan \& Kronick, 2006), less depressive symptoms (Rohrer, Bernard, Zhang, Rasmussen, \& Woroncow, 2008), and better psychological well-being (Robles \& Kiecolt-Glaser, 2003). Despite these positive effects, all couples, including happy couples, experience a range of stressors that can undermine the typical salutary effects of marriage. Specifically, there is robust literature illustrating the negative effects of marital conflict (i.e., disagreements and arguments within marriage; Laursen \& Hafen, 2010; Wright \& Loving, 2011) on health, including poor subjective health (Umberson, Williams, Powers, Liu, \& Needham, 2006), diminished immune and cardiovascular functioning (Coyne et al., 2001; Kiecolt-Glaser et al., 2005), and heightened depression and anxiety symptoms (Choi \& Marks, 2008; Wright \& Loving, 2011).

A shortcoming of this research, however, is that it has not accounted for the multiple ways married couples can experience conflict over the course of their marriage. Some couples disagree or experience irritation on a regular basis, whereas others only disagree on occasion (Birditt, Wan, Orbuch, \& Antonucci, 2017; Choi \& Marks, 2008). Couples can also disagree across several important aspects of marital life, such as money, children, and relationships with in-laws (Oggins, 2003; Tamini, Raghibi, \& Bakhshani, 2012). Furthermore, just as other relationship stressors combine to create and have cumulative effects over time (McCubbin \& McCubbin, 1993, 1996; Totenhagen, Butler, \& Ridley, 2012), we posit that disagreements can also combine to create and have cumulative effects across the life course of marriage. Therefore, it is important to examine multiple dimensions of conflict to gain a more holistic conceptualization and empirical assessment of the various aspects of marital conflict and their unique and joint contributions to spouses' subjective health.

Guided by stress process perspectives (e.g., Pearlin, Menaghan, Lieberman, \& Mullan, 1981; Wickrama, O'Neal, \& Lorenz, 2013), this research conceptualizes marital conflict as a multidimensional stressor to examine how three key aspects of conflict - frequency of disagreements, breadth of disagreements, and a new dimension, which we refer to as cumulative disagreements over time-relate to subjective health. In addition, with women often experiencing worse health outcomes than men after conflict (Kiecolt-Glaser \& Newton, 2001; Wanic \& Kulik, 2011), we assess whether the subjective health consequences of these dimensions of marital conflict function differently for wives and husbands. Finally, given that marital conflict is associated with poorer self-rated health over time (Choi \& Marks, 2008), we use longitudinal data spanning the first 16 years of marriage to examine whether fluctuations in how often spouses disagree and in the number of topics they disagree about, as well as whether disagreements have cumulative effects over 16 years, are associated with subjective health during the early to middle years of marriage. Our goal is to paint a more comprehensive picture of marital conflict and how it contributes to wives' and husbands' subjective health over the marital life course.

\section{1 | Conceptualizing marital conflict}

Stress process theoretical frameworks (e.g., Pearlin et al., 1981; Wickrama et al., 2013) help explain why couples experience poor health outcomes after marital conflict. Stress perspectives define stressors as experiences that challenge individuals' adaptive capacities, which ultimately impact their mental and physical health (Lazarus \& Folkman, 1984; Pearlin, Aneshensel, \& Leblanc, 1997). In the context of marriage, stress frameworks posit that couples encounter various stressors, including normative (e.g., birth of a child) and nonnormative events (e.g., divorce, disability; McCubbin \& McCubbin, 1993, 1996; Randall \& Bodenmann, 2009). Specifically, marital conflict is conceptualized as a normative stressor that occurs in nearly all couples (Wright \& Loving, 2011). Although conflict is a common occurrence, it can be a major source of stress that increases the risk of poor health outcomes, such as 
increased depression and anxiety symptoms (Cano, O'Leary, \& Heinz, 2004) and worse cardiovascular and immune functioning (Coyne et al., 2001; Kiecolt-Glaser et al., 2005).

Stress perspectives also contend that stressors are multidimensional (Randall \& Bodenmann, 2009). People can experience stressors often, stressors can impact multiple areas of individuals' lives, and stressors can pile up over time (McCubbin \& McCubbin, 1993, 1996; Pearlin et al., 1997; Wickrama et al., 2013). Examining the multiple dimensions of stressors can help to tease apart which aspects have implications for spouses' outcomes. Therefore, to better understand how conflict-a marital stressor-is linked to health, we approach conflict with a multidimensional stress lens and assess how several dimensions of conflict within a couple's married life contributes to their subjective health. Given that marital conflict involves disagreements, meaning discordant or incompatible views (Laursen \& Hafen, 2010), we focus on disagreements as marital conflict and examine how three dimensions, including how often couples disagree, the number of topics they disagree about, and the cumulative effects of their disagreements over time, impact wives' and husbands' subjective health.

In studying conflict as a stressor, the frequency of disagreements has been identified as an important dimension of conflict. The frequency of disagreements, defined as how often spouses disagree, is linked to a wide array of poor health outcomes. A higher frequency of disagreements is associated with higher rates of depression, anxiety disorders, chronic illness, and functional health limitations (Choi \& Marks, 2008; Wright \& Loving, 2011), as well as negative health behaviors (O'Farrell, Hooley, Fals-Stewart, \& Cutter, 1998). Consistent with these cross-sectional findings, more frequent disagreements can adversely impact health over time. Among older adults, experiencing frequent disagreements is associated with steeper declines in subjective health over 8 years (Umberson et al., 2006). Likewise, a higher frequency of disagreements is related to increased self-reported functional impairment up to 5 years later, as well as depressive symptoms over 10 years (Choi \& Marks, 2008; Choi \& Marks, 2013).

The breadth of disagreements is another key dimension of marital conflict that contributes to negative health consequences. As posited by stress perspectives, stressors can proliferate, meaning the exposure to one stressor can lead to additional stressors (Pearlin et al., 1997). In viewing marital conflict as a stressor, conflict proliferation can also occur, wherein disagreeing about one topic can lead to disagreements about other topics. Disagreeing across a wide range of issues creates a greater breadth of marital disagreements, defined as the number of topics about which spouses disagree (Morrison \& Coiro, 1999; Oggins, 2003). Disagreements can pervade multiple aspects of a couple's married life; the most disagreed upon topics and biggest challenges in the early years of marriage often include differences over money, relationships with both spouses' in-laws, how to spend leisure time, children, and religion (Papp, Cummings, \& Goeke-Morey, 2009; Storaasli \& Markman, 1990; Williamson, Hanna, Lavner, Bradbury, \& Karney, 2013). An argument about any one of these topics can lead to stress and adversely affect health; however, spouses who disagree about several of these topics (i.e., spouses who have a greater breadth of disagreements) experience even greater levels of stress (Neff \& Karney, 2007). Couples can usually cope with one stressor, but multiple stressors, such as disagreements across a number of issues, can contribute to adverse outcomes (Totenhagen et al., 2012). A greater breadth of marital disagreements is associated with increased physical health symptoms, anxiety, and depression (Tamini et al., 2012), as well as diminished perceived quality of life (Jenewein et al., 2008).

Finally, in addition to the frequency and breadth of disagreements, cumulative disagreements over time might also have implications for married couples' health. Stress frameworks illustrate that the occurrence of stressors over time can have cumulative effects over the marital life course (Wickrama et al., 2013). The long-term exposure to stressors throughout marriage can contribute to cumulative stress (e.g., adversities, risks, disadvantages), regardless of whether the stressors increase or decrease over time. These cumulative effects of stress can overwhelm spouses and wear on their ability to 
cope, ultimately posing threats to their health over time (McCubbin \& McCubbin, 1993, 1996; Wickrama et al., 2013). Applying cumulative stress to marital conflict, we argue that the long-term exposure to marital disagreements - which we refer to as cumulative disagreements - can overwhelm a couple's ability to cope, ultimately increasing their risk of negative health outcomes. The disagreements couples experience over the marital life course might, therefore, combine and contribute to cumulative stress that erodes their adaptational capacities, promoting poorer health over time. Thus, as couples disagree throughout their marriage, the more pervasive disagreements might pile up and have cumulative effects. Over time, spouses who disagree about a variety of issues-for instance, money, child care, religion, and in-laws - might have more cumulative disagreements over the marital life course that negatively impact their health. Therefore, in addition to the frequency and breadth of disagreements, we might expect that cumulative effects of marital disagreements over time would also be linked with poorer health outcomes.

\section{2 | Gender and marital conflict}

The literature also suggests that women are more detrimentally affected by marital conflict compared to men (Kiecolt-Glaser \& Newton, 2001; Wanic \& Kulik, 2011). After conflict, women experience more depressive symptoms (Kouros \& Cummings, 2011) and psychological distress (Noller \& Fitzpatrick, 1990) than men. Laboratory studies show that women are also more likely to show greater physiological distress, such as higher blood pressure and heart rate (Bloor, Uchino, Hicks, \& Smith, 2004), heightened endocrine responses (Fehm-Wolfsdorf, Groth, Kaiser, \& Hahlweg, 1999), and worse immune functioning (Kiecolt-Glaser et al., 1993). Wives also have poorer prognoses after surgery (Kulik \& Mahler, 2006) and higher risks of cardiovascular problems (Coyne et al., 2001) than husbands in distressed marriages. Furthermore, negative aspects of marital functioning have a stronger impact on women's self-health compared to positive aspects of marital functioning (Umberson et al., 2006), and women are more likely to ruminate about relationship conflict and the negative aspects of their relationships (Nolen-Hoeksema \& Jackson, 2001).

The gender differences in the conflict and health link are often explained by women's interdependent self-representations (Kiecolt-Glaser \& Newton, 2001) and their lower status in society (Wanic \& Kulik, 2011). The interpersonal orientation hypothesis asserts that women experience more negative consequences from conflict because they are more interpersonally oriented and tend to base their selfperceptions and identities on their relationships, often due to gendered social roles and socialization (Kiecolt-Glaser \& Newton, 2001; Orbuch, Bauermeister, Brown, \& McKinley, 2013). Because of these interdependent self-representations, women are more likely to be more involved in relationships and to connect with others, as well as to monitor their relationships and identify relationship problems, than men (Cross \& Madson, 1997; Thompson \& Walker, 1991). If issues arise within their relationships, such as conflict, women's self-representations can be damaged because these issues reflect who they are as individuals and as a couple, which takes a toll on their health (Kiecolt-Glaser \& Newton, 2001).

In addition, the subordination-reactivity hypothesis posits that women experience more negative health consequences after conflict because they occupy lower status positions in society and within their marital relationships (Wanic \& Kulik, 2011). Compared to their husbands, wives often have less access to resources, earn lower salaries, and have less prestigious jobs, leading to increased dependence on their husbands (DeNavas-Walt, Proctor, \& Mills, 2004). Husbands also tend to dictate conflict, including when and what they should discuss (Ball, Cowan, \& Cowan, 1995). Husbands, therefore, maintain power by avoiding conflict and denying their wives' requests for change, which ultimately keeps wives in lower status positions (Julien, Arellano, \& Turgeon, 1997). By having less 
power, wives are more dependent on their husbands and vulnerable to health problems, particularly when experiencing marital stress (Wanic \& Kulik, 2011).

Given this body of literature on the health consequences of conflict among women, we might expect that the adverse effects of each dimension of conflict-frequency of disagreements, breadth of disagreements, and cumulative disagreements over time-on subjective health are stronger for wives compared to husbands. Disagreeing often and about several topics in a given year, as well as experiencing cumulative disagreements over 16 years, might be particularly harmful for wives' health, possibly because their perceptions of themselves and their relationships have been damaged, and they often occupy lower status positions within their marriages.

\section{3 | This study}

The negative effects of conflict on marriage (Birditt, Brown, Orbuch, \& Mcllvane, 2010) and on health outcomes (Matthews \& Gump, 2002) have been well documented. This study expands upon existing literature by conceptualizing marital conflict as a multidimensional stressor and tests its subjective health implications across the first 16 years of marriage. Moreover, we propose and test a new dimension of conflict - cumulative disagreements - to assess whether disagreements combine to create cumulative effects over time and harm subjective health. Our dyadic and longitudinal sample allowed us to examine gender differences in the association between the multiple dimensions of conflict and subjective health, as well as whether the effects changed over time. We expected that more frequent disagreements and more breadth of conflict topics within a given year, as well as greater cumulative disagreements over the first 16 years of marriage, would be related to worse subjective health and that these effects would be stronger for wives compared to husbands.

\section{2 | METHOD}

\section{1 | Participants and procedure}

Participants were from the Early Years of Marriage (EYM) Project, a longitudinal panel study following 373 couples (199 Black American and 174 White American) who applied for marriage licenses in Wayne County, MI during a 3-month recruitment period in 1986. A total of $66 \%$ of all couples who applied for marriage licenses during the recruitment period participated in the study. Eligible couples were same-race couples who were entering into their first marriage and in which the wife was younger than 35 years old. All eligible Black American couples and a random sample of the eligible White American couples were contacted for participation (65\% of the Black American couples and $66 \%$ of the White American couples agreed to participate; both members of the couple had to agree to participate). At Year 1, the average ages for husbands and wives were $26(S D=4.15)$ and $24(S D=3.88)$ years, respectively, and the average number of years of education was 13.11 $(S D=1.92)$ for husbands and $13.13(S D=1.89)$ for wives. In addition, the average household income was $\$ 30,933(S D=\$ 16,864)$. The sample fits the demographic profile of the county in 1986 (U.S. Census Bureau, 2004, 2009) and has been compared to a nationally representative sample of first married newlywed individuals in the General Social Survey data from 1980 to 1994. There were no differences by race in the samples regarding income, education, likelihood of cohabitation, parental status, and employment status (see Orbuch, Veroff, Hassan, \& Horrocks, 2002 for additional information), indicating that the EYM Project sample is representative of the U.S. population of first married Black and White newlywed individuals. 
Participants completed face-to-face interviews in their homes with a race-matched interviewer in Years 1, 3, 7, and 16. Spouses were interviewed separately and then together as a couple. The response rate varied across waves, with an average of $80 \%$ of the original sample participating (range 70-93\%; calculated by dividing the total number of husbands or wives interviewed by the number eligible to participate). The response rate for Year 16 was 75\% $(n=528)$, which included 320 married individuals (130 Black Americans and 190 White Americans). Attrition rates also varied across the waves, with $12.5 \%$ of the original sample not located in Year 16 (for a complete description of procedures, see Orbuch et al., 2002). This attrition rate is consistent with other longitudinal studies, such as the National Survey of Families and Households, which reports a 23\% attrition rate for Black Americans and a 15\% rate for White Americans from 1987 to 1994. The divorce rate increased over time from 9\% in Year 2 to $46 \%$ by Year 16. In the third year of the study, $82 \%$ of the couples (149 Black American and 155 White American) were married, and 14\% were divorced or separated. In the seventh year of the study, 65\% of the couples (107 Black American and 135 White American) were married, and 29\% were divorced or separated. By Year 16, 49\% of the couples (75 Black American and 108 White American) were married, and $46 \%$ were divorced or separated. Among married couples at Year 16, the average level of education was 14.16 years $(S D=2.07)$ for wives and $14.01(S D=2.02)$ for husbands, and the household income averaged across husbands and wives was $\$ 66,754(S D=\$ 19,221)$.

\section{2 | Measures}

\subsection{1 | Frequency of marital disagreements}

We assessed the frequency of marital disagreements at each wave by asking respondents to rate the global question of how often they disagree with their spouses. The response options ranged from 1 (almost every day) to 5 (not at all) and was reverse coded, with higher scores indicating more frequent marital disagreements.

\subsection{2 | Breadth of marital disagreements}

The number of disagreement topics at each wave was assessed by asking respondents whether they had any disagreements with their spouses about several topics over the past year $(0=n o, 1=y e s)$. Guided by the literature, the study assessed six common marital disagreement topics: money, children, relationship with the spouse's family, relationship with the respondent's family, how to spend leisure time, and religious beliefs. A count variable was then created for the number of topics that respondents disagreed with their spouses about in the past year, ranging from 0 to 6 topics.

\subsection{3 | Cumulative marital disagreements}

To assess cumulative marital disagreements over the first 16 years of marriage, we summed the number of disagreement topics across each wave. The variable ranged from 0 to 24 , with higher scores indicating greater cumulative marital disagreements over time.

\subsection{4 | Subjective health}

Respondents' subjective general health was measured with seven questions about their health at each wave, including ill health affecting their work, not feeling healthy enough to do things they would like to do, having trouble sleeping or staying asleep, being bothered by nervousness and feeling 
fidgety or tense, being troubled by headaches, and feeling like they were going to have a nervous breakdown. These items are typically found in subjective health measures (e.g., the Short Form Health Survey [SF-36 and SF-12], EQ-5D, and Physical Health Questionnaire; EuroQol Group, 1990; Schat, Kelloway, \& Desmarais, 2005; Ware, Kosinski, \& Keller, 1996; Ware \& Sherbourne, 1992). Response options ranged from 1 (all the time) to 5 (never), and items were averaged such that higher scores indicate better subjective health. Average Cronbach's alpha was .69 across the four waves $^{1}$ (wave $1=.68$, wave $2=.69$, wave $3=.69$, wave $4=.77$ ). For wives, average Cronbach's alpha was .71 (wave $1=.67$, wave $2=.66$, wave $3=.72$, wave $4=.78$ ). For husbands, average Cronbach's alpha was .67 (wave $1=.64$, wave $2=.66$, wave $3=.62$, wave $4=.77$ ). Across the waves, the measure was positively correlated $(r s=.44-.58)$. In addition, spouses who had a serious health issue within the last year scored lower on the subjective health measure compared to spouses without serious health issues at each wave ( $t \mathrm{~s}=-2.91$ to $-7.81, p \mathrm{~s}=.004$ to $<.001$ ). These results provide support for the validity of the measure in assessing spouses' perceptions of their own health consistently over time.

\subsection{5 | Sociodemographic control variables}

Given the effects of education level and household income on subjective health in previous research (Choi \& Marks, 2013; Roxburgh, 2014), respondents' education and income were included as covariates in the analyses. Education was assessed by asking respondents the highest grade in school or year of college they had completed at each wave, ranging from 8 (less than high school) to 17+ (graduate and professional degrees). Household income at each wave was assessed by asking respondents their annual household income before taxes, ranging from 1 (none or less than \$2,999) to 22 (\$75,000 and over). To create a continuous variable, incomes were recoded as the category's midpoint, ranging from $\$ 1,500$ to $\$ 80,000$ (Birditt et al., 2010). In this study, spouses with higher education and income reported better subjective health across the four waves (education $r \mathrm{~s}=.09-.16$; income $r \mathrm{~s}=.14-.25)$.

\section{3 | RESULTS}

\section{1 | Descriptive analyses}

We first conducted several preliminary analyses to describe the extent and congruence of spouses' disagreement topics. On average, wives and husbands disagreed about two or more topics at each wave, with the majority of spouses (46-50\%) disagreeing about two to three topics, followed by zero to one topics (25-41\%) and four to six topics (13-25\%). Spouses disagreed the most about money (72-77\%), followed by kids (19-52\%), how to spend leisure time (34-43\%), their partner's family (27-36\%), their own family (26-39\%), and religion (7-18\%) across the four waves. Chi-square tests of independence showed no association between gender and the reported disagreement topics (i.e., husbands and wives were congruent in reported disagreement topics), with the exception that wives reported more disagreements about their spouse's family (86 reported, 68 expected) than husbands (49 reported, 68 expected) at Years 1, 3, and 16; $\chi^{2}(1)=13.55, p<.001$ (see Orbuch et al., 2013 for effects of in-laws on divorce by gender). Spouses' reported disagreement topics were most congruent for religion (83-90\%) and money (70-74\%), which were the least and most disagreed upon topics at each wave, respectively, followed by kids (60-75\%), leisure time (63-67\%), their own family $(58-71 \%)$, and their spouse's family $(55-63 \%)$. 
We then conducted two-way repeated-measures ANOVAs to examine the change in the frequency of disagreements, the breadth of disagreement topics, and subjective health over time by gender and race. The frequency of disagreements did not change over time by gender or race. Wives and husbands, as well as White Americans and Black Americans, did not differ in the breadth of disagreement topics at each wave. However, spouses disagreed about fewer topics in Year 3 compared to Years 1, 7, and 16; $F(3,675)=14.40, \eta_{\mathrm{p}}^{2}=.06, p<.001$ (see Table 1 for means and standard deviations). There were no differences in breadth of disagreement topics between the other 3 years. Subjective health did not differ by race. However, there was a significant gender by year interaction; $F(2.87,625.83)=2.70, \eta^{2}=.01$, $p=.047$, with wives reporting worse subjective health than husbands at Years 1, 3, and 7 but not Year 16. A two-way ANOVA showed that cumulative disagreements at Year 16 did not differ by gender or race.

Table 2 shows the correlations between the frequency of disagreements, breadth of disagreements, and subjective health at each wave, as well as cumulative disagreements at Year 16, separately for husbands and wives. Correlations were mostly in line with our hypotheses. More frequent disagreements were associated with poorer subjective health among wives at Years 1 and 16 and among husbands at Years 1 and 3, whereas a greater breadth of conflict was related to worse subjective health among wives and husbands across each year. More cumulative disagreements at Year 16 were associated with poorer subjective health among wives, but not husbands, at Year 16.

TABLE 1 Means and standard deviations of study variables by gender

\begin{tabular}{|c|c|c|}
\hline & \multicolumn{2}{|c|}{ Means (SDs) } \\
\hline & Husbands & Wives \\
\hline \multicolumn{3}{|c|}{ Frequency of disagreements } \\
\hline Year 1 & $2.41(0.83)$ & $2.34(0.80)$ \\
\hline Year 3 & $2.21(0.82)$ & $2.32(0.96)$ \\
\hline Year 7 & $2.28(0.83)$ & $2.16(0.81)$ \\
\hline Year 16 & $2.13(0.98)$ & $2.00(0.90)$ \\
\hline \multicolumn{3}{|c|}{ Breadth of disagreements } \\
\hline Year 1 & $2.35(1.45)$ & $2.40(1.45)$ \\
\hline Year 3 & $1.79(1.29)$ & $1.96(1.33)$ \\
\hline Year 7 & $2.48(1.42)$ & $2.45(1.33)$ \\
\hline Year 16 & $2.24(1.43)$ & $2.42(1.46)$ \\
\hline \multicolumn{3}{|c|}{ Cumulative disagreements } \\
\hline Year 1 & - & - \\
\hline Year 3 & - & - \\
\hline Year 7 & - & - \\
\hline Year 16 & $9.23(4.02)$ & $9.39(3.93)$ \\
\hline \multicolumn{3}{|c|}{ Subjective health } \\
\hline Year $1 *$ & $4.03(0.54)$ & $3.71(0.60)$ \\
\hline Year 3* & $4.07(0.52)$ & $3.68(0.58)$ \\
\hline Year 7* & $3.98(0.52)$ & $3.75(0.62)$ \\
\hline Year $16^{*}$ & $3.92(0.65)$ & $3.71(0.71)$ \\
\hline
\end{tabular}

Note: The cumulative disagreements variable was assessed only at Year 16. Mean scores for husbands and wives are significantly different at the $* p<.001$ level. 
T A B LE 2 Associations between study variables within each wave

\begin{tabular}{|c|c|c|c|c|}
\hline & $\begin{array}{l}\text { Frequency of } \\
\text { disagreements }\end{array}$ & $\begin{array}{l}\text { Breadth of } \\
\text { disagreements }\end{array}$ & $\begin{array}{l}\text { Cumulative } \\
\text { disagreements }\end{array}$ & $\begin{array}{l}\text { Subjective } \\
\text { health }\end{array}$ \\
\hline \multicolumn{5}{|c|}{ Frequency of disagreements } \\
\hline Year 1 & & $.26 * * *$ & - & $-.24 * * *$ \\
\hline Year 3 & & $.37 * * *$ & - & $-.23 * * *$ \\
\hline Year 7 & & $.41 * * *$ & - & -.13 \\
\hline Year 16 & & $.40^{* * *}$ & $.40 * * *$ & -.04 \\
\hline \multicolumn{5}{|c|}{ Breadth of disagreements } \\
\hline Year 1 & $.22 * * *$ & & - & $-.25 * * *$ \\
\hline Year 3 & $.31 * * *$ & & - & $-.17^{* *}$ \\
\hline Year 7 & $.31 * * *$ & & - & $-.16^{*}$ \\
\hline Year 16 & $.35^{* * *}$ & & $.79 * * *$ & $-.16^{*}$ \\
\hline \multicolumn{5}{|c|}{ Cumulative disagreements } \\
\hline Year 1 & - & - & & - \\
\hline Year 3 & - & - & & - \\
\hline Year 7 & - & - & & - \\
\hline Year 16 & $.43 * * *$ & $.73 * * *$ & & -.07 \\
\hline \multicolumn{5}{|c|}{ Subjective health } \\
\hline Year 1 & $-.19^{* *}$ & $-.27 * * *$ & - & \\
\hline Year 3 & -.08 & $-.22 * * *$ & - & \\
\hline Year 7 & -.09 & $-.25 * *$ & - & \\
\hline Year 16 & $-.27^{* *}$ & $-.24 * *$ & $-.27 * *$ & \\
\hline
\end{tabular}

Note: Cumulative disagreements were assessed only at Year 16. Correlations for husbands are on the upper diagonal, and correlations for wives are on the lower diagonal. $* p<.05 . ; * *<.01 . ; * * *<.001$.

We also assessed whether each variable was correlated across the four waves separately for husbands and wives, as well as between husbands and wives. ${ }^{2}$ Across the four waves, the frequency of reported disagreements was positively associated for wives $(r \mathrm{~s}=.16-.43)$ and husbands $(r \mathrm{~s}=.16-.44)$, as well as between wives and husbands $(r \mathrm{~s}=.24-.55)$, indicating that more frequent disagreements among wives were linked to more frequent disagreements among husbands. In addition, the number of disagreement topics was positively correlated across the four waves for husbands $(r \mathrm{~s}=.26-.50)$ and wives ( $r s=.29-.41)$, as well as between husbands and wives $(r s=.30-.42)$, such that as husbands' breadth of conflict increased, so did wives'. Wives with greater cumulative disagreements were associated with greater cumulative disagreements among husbands at Year $16(r=.43)$. Finally, subjective health across the four waves was positively correlated for husbands $(r \mathrm{~s}=.39-.52)$ and wives $(r \mathrm{~s}=.46-.56)$, but correlations between husbands' and wives' subjective health were not significant at any of the four waves.

\section{2 | Multilevel models}

Next, we used multilevel modeling (MLM) to test our hypotheses. MLM accounts for nonindependence at both the individual level (e.g., an individual's scores on the same variable over time) 
and dyad level (e.g., both partner's scores on a particular variable over time) by treating time as crossed with individuals nested within dyads (Kenny, Kashy, \& Cook, 2006). We used an autoregressive structure to model the autocorrelation of individuals' scores over time. In addition, a strength of using MLM is that it accounts for missing data by maximizing the use of existing data. All MLM analyses were performed using the MIXED MODELS procedure with restricted maximum likelihood estimation in SPSS version 25.

Prior to conducting the analyses, the independent variables were centered. Spouses' frequency of marital disagreements and breadth of disagreement topics at each wave were centered on their mean score for that variable across the study (i.e., within-person centered; Enders \& Tofighi, 2007). Thus, the frequency of marital disagreements and breadth of disagreement topics at each wave were interpreted as above or below a person's average across the first 16 years of marriage. The cumulative disagreement variable was grand mean-centered because it does not vary over time. For the frequency of disagreements and the breadth of disagreement topics, we tested whether the effects differed by gender and year (i.e., two-way interactions), as well as gender by year (i.e., three-way interactions). For cumulative disagreements, we assessed whether the effects differed by gender.

To assess whether the effects differed by race and gender, we specified a model with two-way and three-way interactions by race and race by gender. These interactions were not significant and were therefore not included in the subsequent analyses. In addition, given that the two-way ANOVAs demonstrated that subjective health did not differ by race, the main effect of race was not controlled for in the analyses (results are consistent with and without race in the models). Continuous control variables were grand mean-centered to improve interpretability of the intercepts. Within dyads, gender (wives $=-1$, husbands $=1$ ) was effects coded.

We first conducted separate models for each conflict variable to assess its effects on subjective health without accounting for the other two dimensions of marital conflict. Results of the first model with the within-person centered frequency of marital disagreements variable indicated that more frequent disagreements within a given year were associated with poorer subjective health $(b=-.05$, $\beta=-.02, p=.02$ ); however, these effects did not differ by gender or year. The second model examining the effects of breadth of marital disagreements demonstrated that disagreeing about more topics than usual within a given year was also related to worse subjective health $(b=-.03, \beta=-.03$, $p=.003$ ), but gender and year did not moderate this association. Finally, the model testing the health implications of cumulative disagreements over 16 years showed that greater cumulative disagreements at Year 16 were associated with poorer subjective health $(b=-.03, \beta=-.13, p<.001)$ and that this effect was stronger for wives than husbands $(b=.02, \beta=.05, p=.03)$. Thus, each of the dimensions of marital conflict was related to subjective health without accounting for their combined effects, meaning that disagreeing more often and about more topics than usual, as well as greater cumulative disagreements over 16 years, were independently linked to poorer health.

Next, to assess how the multiple dimensions of marital conflict jointly relate to subjective health, we tested a model with all three conflict variables (see Table 3 for coefficients). The findings indicated that subjective health declined over time for both wives and husbands, with wives, on average, reporting poorer subjective health than husbands. In addition, higher household income was related to better subjective health. Among the multiple dimensions of conflict, greater cumulative disagreements over the first 16 years of marriage were associated with worse subjective health. Several interactions were significant, including Year $\times$ Gender, Gender $\times$ Cumulative disagreements, and Year $\times$ Gender $\times$ Frequency of disagreements. To examine the significant interactions (i.e., simple slopes), we estimated a second model using the two-intercept approach (Kenny et al., 2006). This 
TA B LE 3 Multilevel regression coefficients predicting subjective health

\begin{tabular}{|lccc|} 
& $\boldsymbol{b}$ & $\boldsymbol{\beta}$ & $\boldsymbol{t}$ \\
\hline Intercept & 3.86 & 3.85 & $-2.74^{* *}$ \\
\hline Year & -.01 & -.06 & $4.47 * *$ \\
\hline Gender & .13 & .12 & 1.32 \\
\hline Education & .02 & .03 & $3.11^{* *}$ \\
\hline Income & .00 & .10 & -1.20 \\
\hline Frequency of disagreements & -.03 & -.01 & -1.05 \\
\hline Breadth of disagreements & -.02 & -.02 & $-4.53 * * *$ \\
\hline Cumulative disagreements & -.03 & -.13 & $-3.03 * *$ \\
\hline Year * gender & -.01 & -.04 & -1.94 \\
\hline Gender * frequency of disagreements & -.05 & -.02 & .37 \\
\hline Gender * breadth of disagreements & .01 & .00 & $2.23 *$ \\
\hline Gender * cumulative disagreements & .02 & .05 & .24 \\
\hline Year * frequency of disagreements & .00 & .01 & -1.13 \\
\hline Year * breadth of disagreements & -.00 & -.02 & $2.02 *$ \\
\hline Gender * year * frequency of disagreements & .01 & .03 & -.57 \\
\hline Gender * year * breadth of disagreements & -.00 & -.02 & \\
\hline
\end{tabular}

Note: Participant gender coded $1=$ male,$-1=$ female.

$* p<.05 . ; * *<.01 . ; * * p<.001$.

approach involves estimating and testing separate coefficients for wives and husbands within the same model.

Probing the two- and three-way interactions for Year $\times$ Gender and Year $\times$ Gender $\times$ Frequency of disagreements, the two-intercept model demonstrated that, although husbands reported better subjective health than wives, husbands' subjective health declined over time $(b=-.02, p<.001)$, whereas wives' health did not change over time $(b=-.00, p=.56)$. Moreover, in years in which spouses reported more frequent disagreements, husbands $(b=-.08, p=.04)$, but not wives $(b=.02$, $p=.52$ ), reported poorer health. Thus, husbands' subjective health became worse over the first 16 years of marriage, and when husbands experienced more marital conflict than usual, they also reported poorer health.

The two-intercept model also demonstrated that, for the Gender $\times$ Cumulative disagreements interaction, greater cumulative disagreements over the first 16 years of marriage were associated with poorer subjective health for wives $(b=-.05, p<.001)$ but not husbands $(b=-.02, p=.10)$. Therefore, for wives, the cumulative effects of disagreeing with their husbands over 16 years were linked to poorer subjective health. Finally, breadth of disagreements (i.e., disagreeing about more or less topics than usual within a given year) and education were not related to subjective health.

\section{4 | DISCUSSION}

Applying stress process perspectives (e.g., Pearlin et al., 1981; Wickrama et al., 2013), this study extended the literature on the conflict-health link by conceptualizing marital conflict as a 
multidimensional stressor and assessing its implications for wives' and husbands' subjective health throughout the early to middle years of marriage. Although previous studies have examined the health implications of how often spouses disagree and how many topics spouses disagree about, this study adds to the literature by identifying a new dimension of marital conflict-cumulative disagreements - as well as simultaneously examining the effects of these multiple dimensions of conflict on spouses' subjective health. Our sample of wives and husbands spanning 16 years also allowed us to examine whether the associations between the various dimensions of conflict and subjective health differed by gender, as well as whether the associations changed over time.

This article contributes to the conflict literature in several ways. First, the findings demonstrated that the multiple dimensions of marital conflict impacted subjective health differently by gender. As expected, the frequency of disagreements and cumulative disagreements was important for subjective health; however, they functioned differently for wives and husbands. For wives, greater cumulative disagreements over the first 16 years of marriage resulted in poorer subjective health. Wives, therefore, might have been able to cope with one disagreement, but as the disagreement topics compiled over the course of their marriage, the cumulative effects eventually wore on their subjective health. In contrast, husbands who reported more frequent disagreements than they usually experienced within a given year had worse subjective health. Therefore, the cumulative effects of marital disagreements over time did not have subjective health consequences for husbands; rather, experiencing a greater number of marital disagreements than they were used to was harmful for their health.

Although we expected the adverse effects of marital conflict on health to be stronger among wives than husbands, there are plausible explanations for these gender differences. For wives, cumulative disagreements over 16 years had negative subjective health implications. This finding can be explained with the interpersonal orientation hypothesis which contends that women experience more negative health consequences due to conflict because their self-perceptions and identities tend to be interconnected or tied to their interpersonal relationships (Kiecolt-Glaser \& Newton, 2001; Orbuch et al., 2013). Cumulative disagreements over 16 years might have been damaging to wives' subjective health because long-term history of disagreements over these issues reflected who they were as individuals and as a couple, which might have damaged their perceptions of themselves, their relationships, and their health.

For husbands, more frequent disagreements than they typically experienced within a given year was linked with poorer subjective health. The subordination-reactivity hypothesis (Wanic \& Kulik, 2011) might provide an explanation for this finding, although in an unexpected way. Although this hypothesis typically predicts poorer health outcomes for women because they often occupy lower status positions in marriages, it might help explain why husbands' health was negatively impacted by their frequent disagreements. By holding a position of power in marital relationships, husbands tend to benefit from avoiding conflict discussions and their wives' requests for change and, therefore, maintain the status quo and their power (Julien et al., 1997). However, in years in which husbands reported more frequent disagreements than they typically experienced, they might have been unable to avoid as many conflict discussions and requests for change, resulting in a felt loss of power in the relationship, which ultimately took a toll on their health. Taken together, both the interpersonal orientation hypothesis and the subordination-reactivity hypothesis may help explain the findings on how various dimensions of marital conflict function differently for wives' and husbands' health.

A second contribution of this research is that, by applying a stress process perspective, we identified marital conflict as a multidimensional stressor. Given that stress is multidimensional, meaning there are several ways in which stress impacts spouses' lives (Randall \& Bodenmann, 2009), we conceptualized conflict - a marital stressor - as multidimensional to examine the diverse and various 
ways in which conflict pervades married life. This approach provided a more comprehensive, holistic approach to conflict and identified various aspects of marital conflict, including the frequency of disagreements, breadth of disagreements, and cumulative disagreements. Through a multidimensional stress lens, this research demonstrated the unique and joint contributions of these key marital conflict dimensions on spouses' subjective health. Although a greater breadth of disagreements in a given year was related to poorer health prior to accounting for the effects of the frequency of disagreements and cumulative disagreements, once we included these other conflict dimensions in the model, breadth of disagreements no longer predicted subjective health. These results demonstrate the importance of examining multiple aspects of marital conflict to demonstrate a more comprehensive understanding on how conflict manifests within marriages and creates health consequences for wives and husbands.

A third contribution is that this research identified a new dimension of conflict by taking a marital life course perspective. Stress process frameworks posit that long-term exposure to stressors over the marital life course combine to create cumulative stress, which can adversely affect health (McCubbin \& McCubbin, 1993, 1996; Wickrama et al., 2013). By applying these perspectives to conflict over the marital life course, this study demonstrated that long-term disagreements across a wide range of issues can compile and compound to create cumulative disagreements that ultimately impact subjective health. Although the frequency and breadth of disagreements have been associated with self-rated health (Choi \& Marks, 2008; Tamini et al., 2012), this is the first study we are aware of to show the adverse effects of cumulative disagreements over time on subjective health. Therefore, just as the cumulative effects of stress over time increase the risk of poor health outcomes, we found that the cumulative effects of disagreeing over the marital life course have negative health consequences.

This study also has several methodological strengths that increase our confidence in the results. First, our sample included husbands and wives and is a diverse and representative sample of Black and White newlywed individuals in the United States (Orbuch et al., 2002). Second, conceptualizing and assessing a multidimensional approach to marital conflict, including the frequency of disagreements, breadth of disagreements, and cumulative disagreements throughout their marriage, furthers our understanding of how conflict manifests within marriages and how multiple aspects of conflict jointly impact spouses' health. Third, the dyadic sample permitted examination of whether the health consequences of the multiple aspects of conflict differed by gender. Fourth, using MLM allowed us to control for the nonindependent nature of data from married couples and the autocorrelation of individuals' data over time. Finally, the longitudinal design permitted examination of the within-person associations to assess whether disagreeing more often and about more topics than usual is harmful for health. Likewise, the longitudinal data spanning 16 years allowed us to assess whether cumulative disagreements over the first 16 years of marriage had negative health consequences.

Although this study has many strengths, it does not come without limitations that must be acknowledged and addressed in future research. First, the measures were self-reported, which may be biased and subject to social desirability. Although perceptions of health and self-reported global health measures are robust predictors of objective health indicators (Idler \& Benyamini, 1997; Jylhä, 2009), future research should assess the effects of cumulative marital disagreements on objective and physiological health measures, such as mortality and morbidity rates, biological health markers, and cortisol reactivity. Second, although the measure of subjective health was positively correlated across time and differentiated between spouses with and without serious health issues, the reliability was not as strong as we would like. The results of this study need to be replicated with additional subjective health measures. In addition, given that our sample was comprised of newlywed couples, we 
were unable to assess whether these findings vary at different developmental stages of marriage. Participants were in the beginning to middle years of marriage, but it is possible that these associations differ across the lifespan and in the later years of marriage. In addition to the developmental context of the marriage, the sociocultural context (e.g., employment status, social network) could be further explored. Although we found that sociocultural factors, such as race and education, were not associated with subjective health, higher income was associated with better subjective health, which is consistent with previous research (Choi \& Marks, 2013).

Furthermore, although we found that greater cumulative marital disagreements over time were associated with poorer subjective health, we did not assess whether disagreeing about the same topic over time also had negative health consequences. However, among spouses still married at Year 16, most did not disagree about the same topics at each wave. Less than half of spouses disagreed about money (43\%) at each wave, followed by how to spend leisure time (8\%), their own family $(8 \%)$, their partner's family (7\%), and children (4\%), with no spouses disagreeing about religion during the four waves. Future research could examine the health implications of disagreeing about the same topics over time. Furthermore, researchers should consider examining disagreement trajectories or typologies over time, including whether the escalation or reduction in disagreement topics relates to subjective health. For instance, the spouses who continually increase their number of disagreement topics might report worse subjective health compared to those who decrease the number of disagreement topics over the course of their marriage. In addition, although this study focused on links between various aspects of marital conflict and subjective health, future work should assess whether appraisals of conflict impact health given their effects during times of stress (Bodenmann, 2005). Researchers should also examine whether protective mechanisms, such as supportive communication or perceived partner responsiveness, alleviate the negative effects of frequent conflicts and cumulative marital disagreements on subjective health. Finally, future work should expand on the gender differences demonstrated in this study by assessing direct and intervening effects of relational power and interdependent identities on husbands' and wives' health.

Considered together, our conceptualization of marital conflict as a multidimensional stressor demonstrated how various aspects of conflict impact subjective health. Furthermore, by testing a new dimension of conflict - cumulative marital disagreements over time - this research showed that, similar to other relationship stressors, conflicts can combine over time and have cumulative negative effects on subjective health. For husbands, disagreeing more often than usual within a given year was associated with poorer subjective health, whereas the cumulative effects of disagreements over the first 16 years of marriage led to worse subjective health for wives. By examining multiple dimensions of conflict simultaneously, these findings demonstrated how various components of conflict relate to wives' and husbands' subjective health in different ways.

\section{ACKNOWLEDGMENTS}

The first author was supported by the Russell J. and Dorothy S. Bilinski Educational Foundation during the preparation of this manuscript. The research in this article was supported by a grant from the National Institute of Child Health and Human Development (HD40778) to the third author.

\section{ORCID}




\section{ENDNOTES}

${ }^{1}$ Removing items did not improve the reliability of the subjective health measure.

${ }^{2}$ These correlations are not displayed in Table 2 but are available from the first author.

\section{REFERENCES}

Ball, F. L., Cowan, P., \& Cowan, C. P. (1995). Who's got the power? Gender differences in partners' perceptions of influence during marital problem-solving discussions. Family Process, 34, 303-321. https://doi.org/10.1111/j. 1545-5300.1995.00303.x

Birditt, K. S., Brown, E., Orbuch, T. L., \& Mcllvane, J. M. (2010). Marital conflict behaviors and implications for divorce over 16 years. Journal of Marriage and Family, 72, 1188-1204. https://doi.org/10.1111/j.1741-3737.2010. 00758.x

Birditt, K. S., Wan, W. H., Orbuch, T. L., \& Antonucci, T. C. (2017). The development of marital tension: Implications for divorce among married couples. Developmental Psychology, 53(10), 1995-2006. https://doi.org/10.1037/ dev0000379

Bloor, L. E., Uchino, B. N., Hicks, A., \& Smith, T. W. (2004). Social relationships and physiological function: The effects of recalling social relationships on cardiovascular reactivity. Annals of Behavioral Medicine, 28, 29-38. https://doi.org/10.1207/s15324796abm2801_5

Bodenmann, G. (2005). Dyadic coping and its significance for marital functioning. In T. A. Revenson, K. Kayser, \& G. Bodenmann (Eds.), Couples coping with stress: Emerging perspectives on dyadic coping (pp. 33-49). Washington, DC: American Psychological Association.

Cano, A., O'Leary, K. D., \& Heinz, W. (2004). Short-term consequences of severe marital stressors. Journal of Social and Personal Relationships, 21, 419-430. https://doi.org/10.1177/0265407504044838

Choi, H., \& Marks, N. F. (2008). Marital conflict, depressive symptoms, and functional impairment. Journal of Marriage and Family, 70, 377-390. https://doi.org/10.1111/j.1741-3737.2008.00488.x

Choi, H., \& Marks, N. F. (2013). Marital quality, socioeconomic status, and physical health. Journal of Marriage and Family, 75, 903-919. https://doi.org/10.1111/jomf.12044

Coyne, J. C., Rohrbaugh, M. J., Shoham, V., Sonnega, J. S., Nicklas, J. M., \& Cranford, J. A. (2001). Prognostic importance of marital quality for survival of congestive heart failure. The American Journal of Cardiology, 88(5), 526-529. https://doi.org/10.1016/S0002-9149(01)01731-3

Cross, S. E., \& Madson, L. (1997). Models of the self: Self-construals and gender. Psychological Bulletin, 122, 5-37. https://doi.org/10.1037/0033-2909.122.1.5

DeNavas-Walt, C., Proctor, B. D., \& Mills, R. J. (2004). Income, poverty, and health insurance coverage in the United States: 2003. Washington, DC: US Government Printing Office.

Enders, C. K., \& Tofighi, D. (2007). Centering predictor variables in cross-sectional multilevel models: A new look at an old issue. Psychological Methods, 12, 121-138. https://doi.org/10.1037/1082-989X.12.2.121

EuroQol Group. (1990). EuroQol - A new facility for the measurement of health-related quality of life. Health Policy, 16(3), 199-208.

Fehm-Wolfsdorf, G., Groth, T., Kaiser, A., \& Hahlweg, K. (1999). Cortisol responses to marital conflict depend on marital interaction quality. International Journal of Behavioral Medicine, 6, 207-227. https://doi.org/10.1207/ s15327558ijbm0603_1

Idler, E. L., \& Benyamini, Y. (1997). Self-rated health and mortality: A review of twenty-seven community studies. Journal of Health and Social Behavior, 38, 21-37.

Jenewein, J., Zwahlen, R. A., Zwahlen, D., Drabe, N., Moergeli, H., \& Büchi, S. (2008). Quality of life and dyadic adjustment in oral cancer patients and their female partners. European Journal of Cancer Care, 17, 127-135. https://doi.org/10.1111/j.1365-2354.2007.00817.x

Julien, D., Arellano, C., \& Turgeon, L. (1997). Gender issues in heterosexual, gay and lesbian couples. In W. K. Halford \& H. J. Markman (Eds.), Clinical handbook of marriage and couples interventions (pp. 107-127). New York: Wiley.

Jylhä, M. (2009). What is self-rated health and why does it predict mortality? Towards a unified conceptual model. Social Science \& Medicine, 69, 307-316. https://doi.org/10.1016/j.socscimed.2009.05.013 
Kaplan, R. M., \& Kronick, R. G. (2006). Marital status and longevity in the United States population. Journal of Epidemiological Community Health, 60, 760-765. https://doi.org/10.1136/jech.2005.037606

Kenny, D. A., Kashy, D. A., \& Cook, W. L. (2006). Dyadic data analysis. New York: Guilford Press.

Kiecolt-Glaser, J. K., Loving, T. J., Stowell, J. R., Malarkey, W. B., Lemeshow, S., Dickinson, S. L., \& Glaser, R. (2005). Hostile marital interactions, proinflammatory cytokine production, and wound healing. Archives of General Psychiatry, 62, 1377-1384. https://doi.org/10.1001/archpsyc.62.12.1377

Kiecolt-Glaser, J. K., Malarkey, W. B., Chee, M., Newton, T., Cacioppo, J. T., Mao, H. Y., \& Glaser, R. (1993). Negative behavior during marital conflict is associated with immunological down-regulation. Psychosomatic Medicine, 55, 395-409. https.//doi.org/10.1097/00006842-199309000-00001

Kiecolt-Glaser, J. K., \& Newton, T. L. (2001). Marriage and health: His and hers. Psychological Bulletin, 127, 472-503. https://doi.org/10.1037//0033-2909.127.4.472

Kouros, C. D., \& Cummings, M. E. (2011). Transactional relations between marital functioning and depressive symptoms. American Journal of Orthopsychiatry, 81, 128-138. https://doi.org/10.1111/j.1939-0025.2010.01080.x

Kulik, J. A., \& Mahler, H. I. M. (2006). Marital quality predicts hospital stay following coronary bypass surgery for women but not men. Social Science \& Medicine, 63, 2031-2040.

Laursen, B., \& Hafen, C. (2010). Future directions in the study of close relationships: Conflict is bad (except when it's not). Social Development, 19, 858-872. https://doi.org/10.1111/j.1467-9507.2009.00546.x

Lazarus, R. S., \& Folkman, S. (1984). Stress, appraisal, and coping. New York: Springer.

Matthews, K. A., \& Gump, B. B. (2002). Chronic work stress and marital dissolution increase risk of posttrial mortality in men from the multiple risk factor intervention trial. Archives of Internal Medicine, 162, 309-315. https://doi.org/ 10.1001/archinte.162.3.309

McCubbin, M., \& McCubbin, H. (1993). Family coping with health crises: The resiliency model of family stress, adjustment, and adaptation. In C. Danielson, B. Hamel-Bissel, \& P. Winstead-Fry (Eds.), Families, health, and illness (pp. 3-63). St. Louis, MO: Mosby.

McCubbin, M., \& McCubbin, H. (1996). Resiliency in families: A conceptual model of family adjustment and adaptation in response to stress and crisis. In H. McCubbin, A. Thompson, \& M. McCubbin (Eds.), Family assessment: Resiliency, coping and adaptation-inventories for research and practice (pp. 1-64). Madison: University of Wisconsin System.

Morrison, D. R., \& Coiro, M. J. (1999). Parental conflict and marital disruption: Do children benefit when high-conflict marriages are dissolved? Journal of Marriage and Family, 61, 626-637. https://doi.org/10.2307/353565

Neff, L. A., \& Karney, B. R. (2007). Stress crossover in newlywed marriage: A longitudinal and dyadic perspective. Journal of Marriage and Family, 69, 594-607. https://doi.org/10.1111/j.1741-3737.2007.00394.x

Nolen-Hoeksema, S., \& Jackson, B. (2001). Mediators of the gender difference in rumination. Psychology of Women Quarterly, 25, 37-47. https://doi.org/10.1111/1471-6402.00005

Noller, P., \& Fitzpatrick, M. A. (1990). Marital communication in the eighties. Journal of Marriage and the Family, $52,832-843$.

O'Farrell, T., Hooley, J., Fals-Stewart, W., \& Cutter, H. S. G. (1998). Expressed emotion and relapse in alcoholic patients. Journal of Consulting and Clinical Psychology, 66, 744-752. https://doi.org/10.1037/0022-006X.66.5.744

Oggins, J. (2003). Topics of marital disagreement among African-American and euro-American newlyweds. Psychological Reports, 92, 419-425. https://doi.org/10.2466/PR0.92.2.419

Orbuch, T. L., Bauermeister, J. A., Brown, E., \& McKinley, B. (2013). Early family ties and marital stability over 16 years: The context of race and gender. Family Relations, 62(2), 255-268. https://doi.org/10.1111/fare.12005

Orbuch, T. L., Veroff, J., Hassan, H., \& Horrocks, J. (2002). Who will divorce: A 14-year longitudinal study of Black couples and White couples. Journal of Social and Personal Relationships, 19, 179-202. https://doi.org/10.1177/ 0265407502192002

Papp, L. M., Cummings, E. M., \& Goeke-Morey, M. C. (2009). For richer, for poorer: Money as a topic of marital conflict in the home. Family Relations, 58, 91-103. https://doi.org/10.1111/j.1741-3729.2008.00537.x

Pearlin, L. I., Aneshensel, C. S., \& Leblanc, A. J. (1997). The forms and mechanisms of stress proliferation: The case of AIDS caregivers. Journal of Health and Social Behavior, 38(3), 223-236. https://doi.org/10.2307/2955368

Pearlin, L. I., Menaghan, E. G., Lieberman, M. A., \& Mullan, J. T. (1981). The stress process. Journal of Health and Social Behavior, 22, 337-356. 
Randall, A. K., \& Bodenmann, G. (2009). The role of stress on close relationships and marital satisfaction. Clinical Psychology Review, 29(2), 105-115. https://doi.org/10.1016/j.cpr.2008.10.004

Robles, T. F., \& Kiecolt-Glaser, J. K. (2003). The physiology of marriage: Pathways to health. Physiology \& Behavior, 79(3), 409-416. https://doi.org/10.1016/S0031-9384(03)00160-4

Rohrer, J. E., Bernard, M. E., Zhang, Y., Rasmussen, N. H., \& Woroncow, H. (2008). Marital status, feeling depressed and self-rated health in rural female primary care patients. Journal of Evaluation in Clinical Practice, 14, $214-217$. https://doi.org/10.1111/j.1365-2753.2007.00835.x

Roxburgh, S. (2014). Race, class, and gender differences in the marriage-health relationship. Race, Gender \& Class, $21,7-31$.

Schat, A. C. H., Kelloway, E. K., \& Desmarais, S. (2005). The physical health questionnaire (PHQ): Construct validation of a self-report scale of somatic symptoms. Journal of Occupational Health Psychology, 10(4), 363-381. https://doi.org/10.1037/1076-8998.10.4.363

Storaasli, R. D., \& Markman, H. J. (1990). Relationship problems in the early stages of marriage: A longitudinal investigation. Journal of Family Psychology, 4, 80-98. https://doi.org/10.1037/0893-3200.4.1.80

Tamini, K. B., Raghibi, M., \& Bakhshani, N. (2012). A study of mental health and dyadic adjustment between smokers and nonsmokers. International Journal of High Risk Behaviors \& Addiction, 1, 55-60. https://doi.org/10.5812/ ijhrba.4175

Thompson, L., \& Walker, A. J. (1991). Gender in families: Women and men in marriage, work, and parenthood. In A. Booth (Ed.), Contemporary families: Looking forward, looking back (pp. 76-102). Minneapolis, MN: National Council on Family Relations.

Totenhagen, C. J., Butler, E. A., \& Ridley, C. A. (2012). Daily stress, closeness, and satisfaction in gay and lesbian couples. Personal Relationships, 19, 219-233. https://doi.org/10.1111/j.1475-6811.2011.01349.x

U.S. Census Bureau (2004, 2009). Intercensal county estimates by age, sex, and race: 1986. Retrieved from https:// www.census.gov/data/tables/time-series/demo/popest/1980s-county.html

Umberson, D., Williams, K., Powers, D. A., Liu, H., \& Needham, B. (2006). You make me sick: Marital quality and health over the life course. Journal of Health and Social Behavior, 47, 1-16. https://doi.org/10.1177/ 002214650604700101

Wanic, R., \& Kulik, J. (2011). Toward an understanding of gender differences in the impact of marital conflict on health. Sex Roles, 65, 297-312. https://doi.org/10.1007/s11199-011-9968-6

Ware, J. E., Kosinski, M., \& Keller, S. D. (1996). A 12-item short-form health survey: Construction of scales and preliminary tests of reliability and validity. Medical Care, 34, 220-233.

Ware, J. E., \& Sherbourne, C. D. (1992). The MOS 36-item short-form health survey (SF-36): I. Conceptual framework and item selection. Medical Care, 30, 473-483.

Wickrama, K. A. S., O'Neal, C. W., \& Lorenz, F. O. (2013). Marital functioning from middle to later years: A life course-stress process framework: Marital functioning in later life. Journal of Family Theory \& Review, 5(1), 15-34. https://doi.org/10.1111/jftr.12000

Williamson, H., Hanna, M., Lavner, J., Bradbury, T., \& Karney, B. (2013). Discussion topic and observed behavior in couples' problem-solving conversations: Do problem severity and topic choice matter? Journal of Family Psychology, 27, 330-335. https://doi.org/10.1037/a0031534

Wright, B. L., \& Loving, T. J. (2011). Health implications of conflict in close relationships. Social and Personality Psychology Compass, 5, 552-562. https://doi.org/10.1111/j.1751-9004.2011.00371.x

How to cite this article: Shrout MR, Brown RD, Orbuch TL, Weigel DJ. A multidimensional examination of marital conflict and subjective health over 16 years. Pers Relationship. 2019;26:490-506. https://doi.org/10.1111/pere.12292 